\title{
Analysis and Control Design for a Class of Fractional Order Time-Delay Systems
}

\author{
Marwa BOUDANA ${ }^{(1)^{*}}$, Samir LADACI ${ }^{(1,2)}$, Jean Jacques LOISEAU ${ }^{(3)}$ \\ (1) Department of E.E.A. National polytechnic school of Constantine ENPC, Constantine, Algeria \\ (2) Laboratoire de Traitement du Signal, SP-Lab, Mentouri University of Constantine, Algeria. \\ (3) LS2N-CNRS, Ecole central de Nantes, Nantes, France. \\ marouaboudana7@gmail.com; samir ladaci@yahoo.fr; jean-jacques.loiseau@Is2n.fr
}

\begin{abstract}
In this paper, we consider a class of fractional order time-delay systems and propose a fractional order $\mathrm{PI}^{\lambda} \mathrm{D}^{\mu}$ control design for their stabilization. The controller parameter's adjustment is achieved in two steps: first, the relay approach is used to compute satisfactory classical PID coefficients, namely $\mathrm{kp}, \mathrm{Ti}$ and $\mathrm{Td}$. Then, the fractional orders $\lambda$ and $\mu$ are optimized using performance criteria. Simulation results show the efficiency of the proposed design technique and its ability to enhance the PID control performance.
\end{abstract}

Keywords: Fractional order control, Time-delay systems, Fractional $\mathrm{Pl}^{\lambda} \mathrm{D}^{\mu}$ controller, Relay method, Parameters adjustment.

\section{INTRODUCTION}

Fractional calculus is an old mathematical analysis concept which is attracting great interest nowadays [1-3]. Initially introduced pure mathematics, recently, FC has invested various engineering domains [4-5]. Fractional order models have proven to better represent many physical systems, like dielectric polarization, semi-infinite transmission lines, viscoelasticity...etc. [6]. In the automatic control engineering field, an important effort is done towards design and development and application of fractional order controllers with various control strategies [7-8].

Recently, a great number of researchers focused their work on the stability analysis of fractional order time-delay systems [9-12]. Finite-time stability has been investigated in [13-15], while different stability criteria for this class of systems have been proposed in literature [16-20]. Stability of linear fractional order systems with delays has been studied in many papers [21], also fractional-order nonlinear systems with delay [22-23], neutral fractional-delay systems [24-25] and fractional-order time-varying delay systems [26].

In the field of control engineering, the introduction of fractional operators and systems has proven certain ability for performance enhancement [27]. One of the pioneering works was developed by
Podlubny in 1999 who has proposed a generalized form for PID controllers, namely $\mathrm{PI} \lambda \mathrm{D} \mu$ controllers, using an integrator of order $\lambda$ and a differentiator of order $\mu$ (where $\lambda$ and $\mu$ have real values) [28]. He showed that the fractional order PID control improves the control system performance in comparison with the classical PID controller because of the extra real parameters $\lambda$ and $\mu$ involved. The implementation of this fractional controller needs these non-integer operators to be approximated, using frequency domain approximations such as Oustaloup's method [29] and Charef's method [30]...

However the problem of PID controllers' tuning remains an important issue [31-32]. There exist many adjusting techniques that do not require any model of the plant to control. All that is needed to apply such rules is to have time response of the plant. Examples of such sets of rules are those due to Ziegler and Nichols, Cohen and Coon, and the Kappa-Tau rules [33]. In particular, the Ziegler-Nichols method [34] still remains popular, particularly in industry. An interesting similar modern approach is based on the relay auto tuning [35].

In this paper, a fractional order PI $\lambda$ and $\mathrm{PI} \lambda \mathrm{D} \mu$ control design technique is proposed for a class of fractional order Time-Delay systems. The controller parameter's adjustment is achieved in two steps: first, the relay approach is used to compute satisfactory classical PID coefficients, namely 
$\mathrm{kp}$, Ti and Td. Then, the fractional orders $\lambda$ and $\mu$ are optimized using performance criteria.

This paper is organized as follows: In Section 2 , the design of both integer order PI and PID controllers with relay feedback method is given. Charef's approximation method for fractional order systems is introduced in Section 3, whereas the proposed design methodology for fractional order PI and PID controllers is given in section 4 . In section 5 , simulation examples about integer and fractional time delay systems are presented. Concluding remarks are given in Section 6.

\section{DESIGN OF INTEGER ORDER PID CONTROLLERS FOR TIME-DELAY SYSTEMS}

$$
\begin{gathered}
C(s)=k_{p}\left(1+\frac{1}{T_{i} s}\right) \\
G(s)=\frac{Z_{m} s^{m}+Z_{m-1} s^{m-1}+\cdots+Z_{0}}{q_{n} s^{n}+q_{n-1} s^{n-1}+\cdots+q_{0}}
\end{gathered}
$$

Where zi, qi are real parameters and $\mathrm{m}, \mathrm{n}$ are integer positive numbers.

The open loop transfer function ( $L(s)$ ) of the control system is given as,

$$
L(s)=C(s) G(s)
$$

The transfer function of integer order PID is given by

$$
C(s)=k_{p}\left(1+\frac{1}{T_{i} s}+T_{d} s\right)
$$

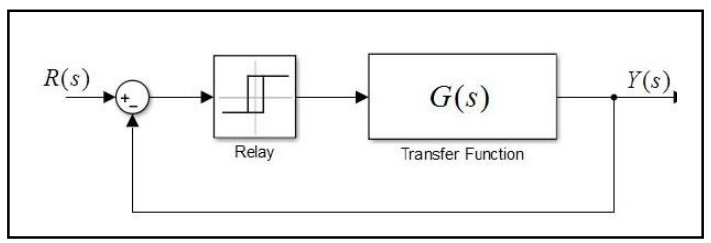

Fig. 1 Relay feedback of integer plant.

The relay method is based on determining the critical gain and the critical frequency [36] as illustrated in the Matlab Simulink diagram of Fig. 1. The relay input-output characteristic is given in Fig. 2 and the relay output is shown in Fig. 3.

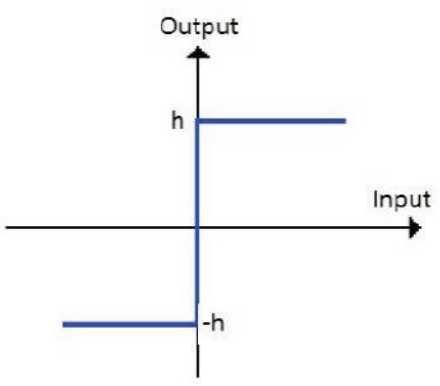

Fig. 2 Relay input-output characteristic.

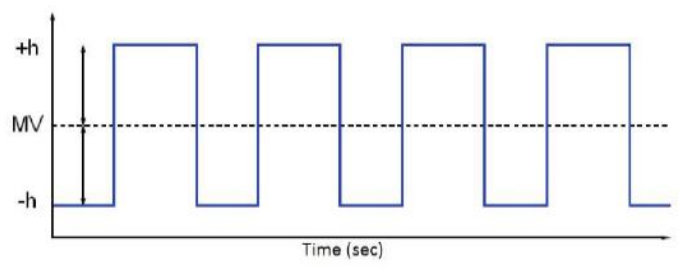

Fig. 3 Relay output.

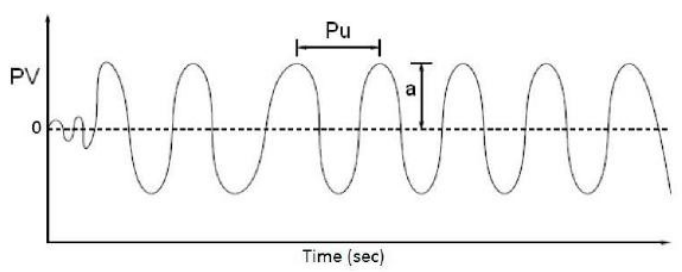

Fig. 4 Output of closed loop control system with relay.

For a typical plant the oscillation obtained in the test occurring at the relay input is as shown in Figure 4. The critical frequency is taken as the measured frequency and the critical gain $\mathrm{Ku}$ is obtained by the formula,

$$
K_{u}=\frac{4 h}{\pi a}
$$

Where $h$ represents the amplitude of the relay actuation and $a$ is the amplitude of the resulting oscillation. Both the values for the critical frequency and gain are approximate values based on using the describing function analysis for the system.

From the values of critical gain $K_{u}$ and ultimate period $P_{u}$, the controller parameters, $\left(k_{p}, T_{i}\right.$ and $\left.T_{d}\right)$ for the P, PI, and the PID gains are computed from Table 1 using the closed-loop Z-N method. 
Table 1 ZIEGLER NICHOLS FORMULA

\begin{tabular}{|l|l|l|l|}
\hline & \multicolumn{1}{|c|}{$k_{p}$} & \multicolumn{1}{c|}{$T_{i}$} & \multicolumn{1}{c|}{$T_{d}$} \\
\hline$P$ & $K_{u} / 2$ & & \\
\hline$P I$ & $K_{u} / 2.2$ & $P_{u} / 1.2$ & \\
\hline$P I D$ & $K_{u} / 1.7$ & $P_{u} / 2$ & $P_{u} / 8$ \\
\hline
\end{tabular}

\section{CHAREF'S APPROXIMATION METHOD FOR FRACTIONAL ORDER SYSTEMS}

This method proposed by Charef et al. [30], is based on the approximation of a function of the form:

$$
H(s)=\frac{1}{\left(1+\frac{s}{p_{T}}\right)^{\alpha}}
$$

Where $1 / P_{T}$ is the relaxation time constant and $0<\propto<1$.

$$
H(s)=\frac{\prod_{i=0}^{n-1}\left(1+\frac{s}{z_{i}}\right)}{\prod_{i=0}^{n}\left(1+\frac{s}{p_{i}}\right)}
$$

We define:

$$
a=10^{\left(\frac{y}{10(\alpha-1)}\right)}, b=10^{\left(\frac{y}{10 \alpha}\right)}, a b=10^{\left(\frac{y}{10 \alpha(\alpha-1)}\right)}
$$

Therefore, we can obtain the distribution of poles and zeros as:

$$
p_{0}=p_{T} \sqrt{b}, p_{i}=p_{0}(a b)^{i}, z_{i}=a p_{0}(a b)^{i}(9)
$$

\section{Fractional order $\mathrm{PI}^{\Lambda} \mathrm{D}^{\mu}$ controller realization:}

The transfer function of the fractional order $\mathrm{PI}^{\lambda} \mathrm{D}^{\mu}$ controller is given in the frequency domain by the following irrational function,

$$
C(s)=K_{p}+\frac{T_{I}}{s^{\lambda}}+T_{D} s^{\mu}
$$

Where $K_{p}$ is the proportional constant, $T_{i}$ is the integration constant, $T_{D}$ is the differentiation constant and $\lambda$ and $\mu$ are positive real numbers.

In general, these real numbers are such that, $1<\lambda<2$ and $1<\mu<2$. Hence, (10) can be written as:
$C(s)=K_{p}+\left[\frac{T_{I}}{s}\right]\left(\frac{1}{s^{m 1}}\right)+\left[T_{D} s\right]\left(s^{m 0}\right)$

(11)

Where $\left(T_{I} / s\right)$ is a first-order integrator, $\left(1 / s^{m}\right)$ is fractional order integrator with $0<m_{1}<1, \quad\left(T_{D} s\right)$ is a first oredr differentiator and $\left(s^{m 0}\right)$ is a fractional order differentiator with $0<m_{D}<1$.

In order to represent the fractional $P I^{\lambda} D^{\mu}$ controller of (10) by a linear time-invariant system model, it is necessary to approximate its irrational transfer function by a rational one. Hence, in a given frequency band of practical interest $\left(w_{L}, w_{H}\right)$, the fractionalorder integrator can be modeled by an FPP and the fractional-order differentiator by an FPZ.

$$
\begin{aligned}
& C(s)=K_{p}+\left[\frac{T_{I}}{s}\right]\left(K_{I} \frac{\prod_{i=0}^{N_{I}-1}\left(1+\left(s / z_{I_{i}}\right)\right)}{\prod_{i=0}^{N_{I}}\left(1+\left(s / p_{I_{i}}\right)\right)}\right) \\
& +\left[T_{D} s\right]\left(\left(K_{D} \frac{\prod_{i=0}^{N_{D}-1}\left(1+\left(s / z_{D_{i}}\right)\right)}{\prod_{i=0}^{N_{D}}\left(1+\left(s / p_{D_{i}}\right)\right)}\right)\right)
\end{aligned}
$$

\section{FRACTOIONAL PID CONTROLLER DESIGN}

Fractional order $\mathrm{Pl}^{\lambda} \mathrm{D}^{\mu}$ parameters adjustment remains one of the major issues in fractional order control domain [37]. This control design technique is proposed for a class of fractional order Time-Delay systems. The controller parameter's adjustment is achieved in two steps:

- First, the relay approach is used to compute satisfactory classical PID coefficients, namely kp, ki and kd.

- Then, the fractional orders $\lambda$ and $\mu$ are optimized using performance specifications like the rise time, the peak time, the settling time, and the overshoot and the following and quadratic error performance criteria,

$$
J=\sqrt{\int_{0}^{t_{f}} e(t)^{2} d t}
$$


The cost function $\mathrm{J}$ is minimized relatively to the fractional integral and derivative orders in order to find the best controller tuning.

\section{SIMULATION EXAMPLES}

Consider a delayed plant represented by its transfer function,

$$
G(s)=\frac{26 e^{-s}}{16.2 s+1}
$$

The step response of the closed loop system with unity feedback is shown in Fig. 5. which is an oscillating response.

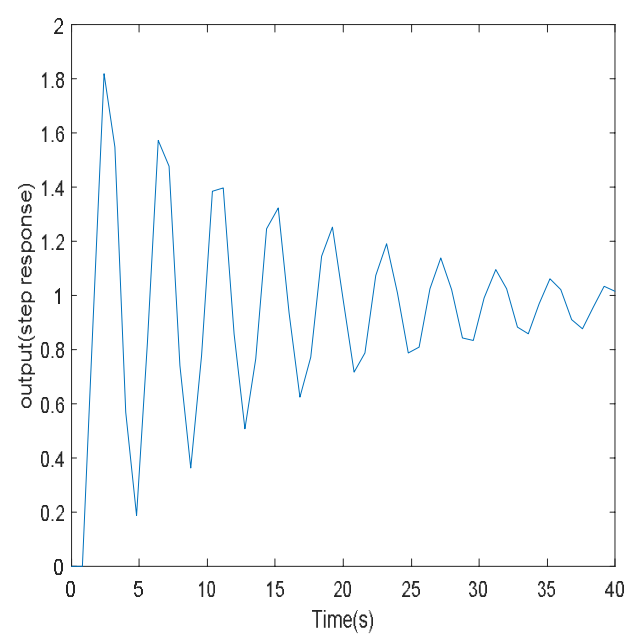

Fig. 5 Step response of the closed loop system with unit feedback.

From the Simulink diagram shown in Fig. 5, critical values are calculated. And from Fig. 6 we obtain the parameters shown in Table 2.

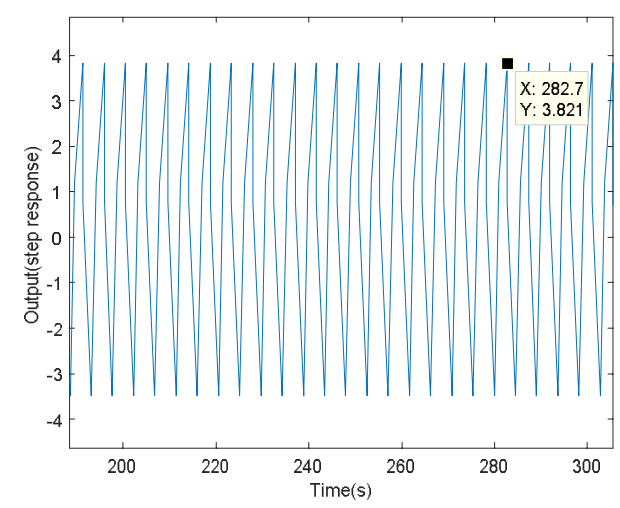

Fig. 6 Output of closed loop of control system with relay.
Table 2 Critical values using the relay method

\begin{tabular}{|c|c|}
\hline Amplitude (a) & 5.881 \\
\hline Oscillating period $(\mathrm{Pu})$ & 8.9 \\
\hline Critical gain $(\mathrm{Ku})$ & 0.43 \\
\hline
\end{tabular}

\section{E. Design of PI controller}

The design of $\mathrm{PI}$ controller using table 1 , is given by:

$$
\begin{aligned}
& k_{p}=\frac{K_{u}}{2.2}=\frac{0.43}{2.2}=0.195 \\
& T_{i}=\frac{P_{u}}{1.2}=\frac{8.9}{1.2}=7.417
\end{aligned}
$$

From these parameters, we obtain both, integer and fractional order PI controllers as follow:

$$
\begin{aligned}
& C(s)=0.195\left(1+\frac{0.135}{s}\right) \\
& C_{F}(s)=0.195\left(1+\frac{0.135}{s^{\lambda}}\right)
\end{aligned}
$$

The step response of closed loop control system with both integer and fractional PI controllers are shown in Fig. 7.

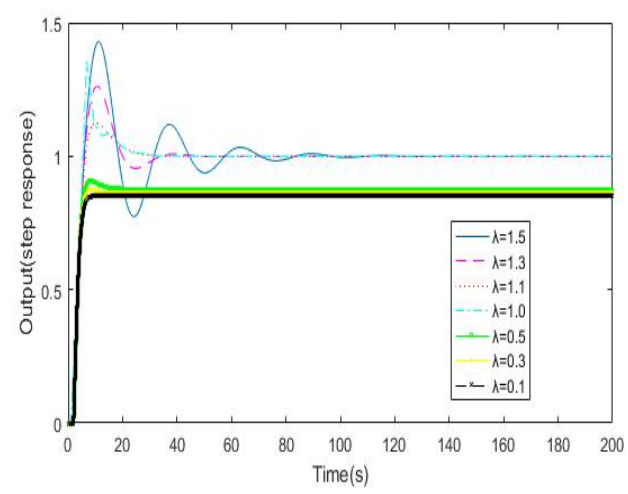

Fig. 7 Step responses of closed loop control system with fractional $\mathrm{PI}$ controller for different values of $\lambda$.

Specification values for the step responses for different $\lambda$ are given in Table 3 .

Table 3 Step Response Performance Values for Different Values of $\lambda$.

\begin{tabular}{|c|c|c|c|c|c|c|}
\hline \multirow{2}{*}{$\Lambda$} & \multirow{2}{*}{$t_{r}(s)$} & \multirow{2}{*}{$t_{p}(s)$} & $2 \%$ & $5 \%$ & \multirow{2}{*}{$M_{p}(\%)$} & \multirow{2}{*}{$J$} \\
\hline 1.5 & 5.38 & 11.19 & 67.23 & 52.95 & 44.20 & 3.71 \\
\hline 1.3 & 5.32 & 10.64 & 19.13 & 18.06 & 25.95 & 2.54 \\
\hline 1.1 & 3.16 & 10.47 & 22.52 & 17.89 & 13.07 & 2.20 \\
\hline
\end{tabular}




\begin{tabular}{|c|c|c|c|c|c|c|}
\hline$\Lambda$ & \multirow{2}{*}{$t_{p}(s)$} & \multirow{2}{*}{$t_{p}(s)$} & $2 \%$ & $5 \%$ & ${ }^{*} M_{p}(\%)$ & \multirow{2}{*}{$J$} \\
\hline 1.5 & 5.38 & 11.19 & 67.23 & 52.95 & 44.20 & 3.71 \\
\hline 1.0 & 5.06 & 6.78 & 22.32 & 18.56 & 36.30 & 2.28 \\
\hline 0.5 & 5.04 & 8.23 & 11.64 & 5.48 & 3.65 & $\infty$ \\
\hline 0.3 & 5.07 & 8.32 & 6.10 & 5.60 & 1.53 & $\infty$ \\
\hline 0.1 & 5.25 & - & 6.93 & 5.99 & - & $\infty$ \\
\hline
\end{tabular}

$$
C_{F}(s)=0.25\left(1+\frac{0.23}{s^{\lambda}}+1.11 s^{\mu}\right)
$$

The step responses of closed loop control system with integer and fractional order PID controllers are shown in Fig. 9.

Specification values for the step responses for different values of $\lambda$ and $\mu$ are given in table 4.

Table 4 shows that, when the value of $\lambda$ is fixed at 1.1 in the range (1.1-1.5) for values of $\mu$, values of rise time, peak time, settling time and overshoot decrease with decreasing the value of $\mu$, with a finite quadratic error at steady state. And the best value of $\mu$ which give us the best performances is equal to 1.1.

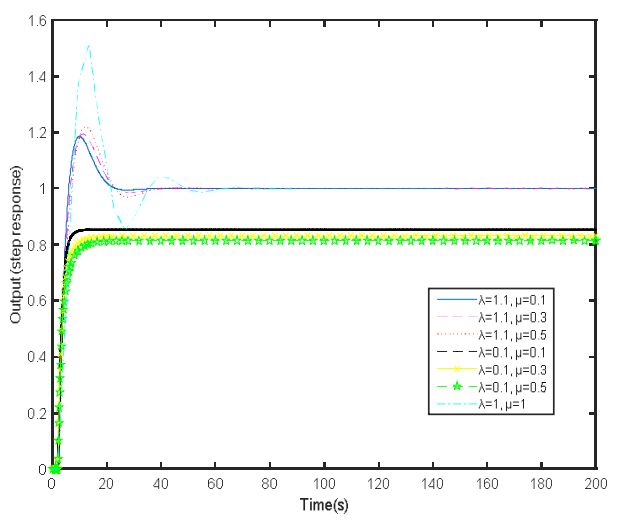

Fig. 9. Step responses of closed loop control system with fractional PID controllers for different values of $\lambda$ and $\mu$.

Table 4 Step Response Performance Values for Different Values of $\lambda$ and $\mu$

\begin{tabular}{|c|c|c|c|c|c|c|c|}
\hline \multirow{2}{*}{$\Lambda$} & \multirow{2}{*}{$\mu$} & \multirow{2}{*}{$t_{r}(s)$} & \multirow{2}{*}{$t_{p}(s)$} & \multicolumn{2}{|c|}{$t_{s}(s)$} & \multirow{2}{*}{$M_{p}(\%)$} & \multirow{2}{*}{$J$} \\
\hline & & & & $2 \%$ & $5 \%$ & & \\
\hline 1.1 & 1.5 & 6.14 & 12.06 & 32.20 & 20.33 & 22.84 & 2.45 \\
\hline 1.1 & 1.3 & 5.74 & 11.59 & 21.42 & 19.44 & 19.88 & 2.32 \\
\hline 1.1 & 1.1 & 5.29 & 9.97 & 20.00 & 17.59 & 18.45 & 2.24 \\
\hline 1.0 & 1.0 & 6.74 & 13.47 & 45.72 & 32.80 & 50.76 & 3.73 \\
\hline 0.1 & 0.5 & 6.84 & - & 11.44 & 8.81 & - & $\infty$ \\
\hline 0.1 & 0.3 & 6.02 & - & 10.44 & 7.80 & - & $\infty$ \\
\hline 0.1 & 0.1 & 5.17 & - & 7.218 & 6.03 & - & $\infty$ \\
\hline
\end{tabular}

Otherwise, choosing values of $\lambda$ and $\mu$ less than zero give an infinitive quadratic error in steady state which means an unstable system despite the good values of other performances. 


\section{CONCLUSION}

In this paper, a simple and efficient methodology for fractional order PID control design for a class of fractional order systems with delay is proposed.

The controller parameter's adjustment is achieved in two steps: first, the relay approach is used to compute satisfactory classical PID coefficients, namely $\mathrm{kp}, \mathrm{Ti}$ and $\mathrm{Td}$. Then, the fractional orders $\lambda$ and $\mu$ are optimized using performance criteria. Simulation results show the efficiency of the proposed design technique and its ability to enhance the fractional order PID control performance.

\section{References}

[1] S. Ladaci, J.J. Loiseau, and A. Charef, Fractional Order Adaptive High-Gain Controllers for a Class of Linear Systems. Communications in Nonlinear Science and Numerical Simulations, 13(4), 707-714, 2008.

[2] S. Ladaci, and A. Charef, Fractional order adaptive control systems: A survey. In: E.W. Mitchell, \& S.R. Murray (Ed.), Classification and Application of Fractals (pp. 261-275). USA, Nova Science Publishers, Inc.2012.

[3] K. Rabah, S. Ladaci, and M. Lashab, A Novel Fractional Sliding Mode Control Configuration for Synchronizing Disturbed Fractional order Chaotic Systems. Pramana, 89 (3), 46. 2017.

[4] S. Ladaci, and A. Charef, On fractional adaptive control. Nonlinear Dynamics, 43(4), 365-378, 2006.

[5] Petráš, Fractional-order nonlinear systems: modeling, analysis and simulation. Berlin Heidelberg, SpringerVerlag, \& Beijing, Higher Education Press. 2011.

[6] Schmidt, and L. Gaul, Application of fractional calculus to viscoelastically damped structures in the finite element method. In Proceedings of International conference on structural dynamics modelling (pp. 297-306), 2002.

[7] K. Khettab, S. Ladaci, and Y. Bensafia, Fuzzy adaptive control of fractional order chaotic systems with unknown control gain sign using a fractional order Nussbaum gain. IEEE/CAA Journal of Automatica Sinica, 6(3), 816-823, 2019.

[8] V. Vafaei, H. Kheiri, and A.J. Akbarfam, Synchronization of fractional-order chaotic systems with disturbances via novel fractional-integer integral sliding mode control and application to neuron models. Mathematical Methods in the
Applied Sciences, 42(8), 2761-2773, 2019.

[9] M.P. Lazarević, Stability and Stabilization of Fractional Order Time Delay Systems. Scientific Technical Review, 61(1), 31-45. 2011.

[10] L . Zhang, Z.-Z., Mao, X.-G., Li, S.-I., Niculescu, and A. Cela, Complete Stability of Linear Fractional Order Time Delay Systems: A Unified FrequencySweeping Approach. In Proceedings of the 35th Chinese Control Conference (pp. 1605-1609), July 27-29, Chengdu, China, 2016.

[11] Li, S.-M., Zhong, and H.-B. Li, Stability Analysis of Fractional Order Systems with Time Delay. International Journal of Mathematical and Computational Sciences, 8(4), 660-663, 2014.

[12] B.-B. He, H.-C. Zhou, Y.Q., Chen, and C.-H. Kou, Asymptotical stability of fractional order systems with time delay via an integral inequality, IET Control Theory \& Applications, 12(12), 17481754, 2018.

[13] M.P.Lazarević, and A.M. Spasić, Finitetime stability analysis of fractional order time-delay systems: Gronwall's approach. Mathematical and Computer Modelling, 49, 475-481, 2009.

[14] L. Chen, Y. He, R. Wu, Y. Chai, and L. Yin, Robust Finite Time Stability of Fractional-order Linear Delayed Systems with Nonlinear Perturbations. International Journal of Control, Automation, and Systems, 12(3), 697702, 2014.

[15] O. Naifar, A. M., Nagy, A., Ben Makhlouf, M. Kharrat, and M. A. Hammami, Finitetime stability of linear fractional-order time-delay systems. International journal of robust and nonlinear control, 29(1), 180-187, 2019.

[16] C. Hwang, and Y.C. Cheng, A numerical algorithm for stability testing of fractional delay systems. Automatica, 42(5), 825831, 2006.

[17] F. Merrikh-Bayat, and M. KarimiGhartemani, An efficient numerical algorithm for a stability testing of fractional-delay systems. Transactions, 48(1), 32-37, 2009.

[18] M. Shi, and Z.H. Wang, An effective analytical criterion for stability testing of fractional-delay systems. Automatica, 47, 2001-2005, 2011.

[19] A. R. Fioravanti, C. Bonnet, H. Ozbay, and S.-I. Niculescu, A numerical method for stability windows and unstable rootlocus calculation for linear fractional timedelay systems. Automatica, 48(11), 2824-2830, 2012.

[20] Z. Gao, A computing method on stability intervals of timedelay for fractional-order 
retarded systems with commensurate time-delays. Automatica, 50, 1611-1616, 2014.

[21] M. BusłowiczStability of linear continuous-time fractional order systems with delays of the retarded type. Bulletin of The Polish Academy of Sciences Technical Sciences, 56(4), 319-324, 2008.

[22] M.P. Lazarević, and D. Lj. Debeljkovic, Robust finite time stability of nonlinear fractional order time delay systems. International Journal of Information and Systems Sciences, 4(2), 301-315, 2008.

[23] Y. Wang, and T. Li, Stability Analysis of Fractional-Order Nonlinear Systems with Delay. Mathematical Problems in Engineering, Volume 2014, Article ID 301235, 8 pages, 2014.

[24] C. Bonnet, and J. R. Partington, Analysis of fractional delay systems of retarded and neutral type. Automatica, 38, 11331138, 2002.

[25] Q. Xu, M. Shi, and Z. Wang, Stability and delay sensitivity of neutral fractionaldelay systems. Chaos, 26, 084301, pp. 1-10, 2016.

[26] Y.Boukal, M. Zasadzinski, M. Darouach, and N.E. Radhy, Stability and stabilizability analysis of fractional-order time-varying delay systems via diffusive representation. In Proceedings of the 2016 5th International Conference on Systems and Control (pp. 262-266), Cadi Ayyad University, Marrakesh, Morocco, May 25-27, 2016.

[27] S. Li, and Y. Q. Chen, A Fractional Order Proportional and Derivatives (FOPID): Controller Tuning Algorithm. In Proceedings of Chinese Control and Decision Conference (pp. 4059-4063), 2008.

[28] Podlubny, Fractional-order systems and PIXD $\mu$-controllers. IEEE Transaction on Automatic Control, 44(1), 208-214, 1999.

[29] A., Oustaloup, F. Levron, B. Mathieu, and M. F. Nanot, Frequency-Band Complex Noninteger Differentiator: Characterization and Synthesis. IEEE Trans. on Circuits and Systems-I: Fundamental Theory and applications, 47(1), 25-39, 2000.

[30] A. Charef, H. H. Sun, Y. Y. Tsao, and B. Onaral, Fractal System as represented by singularity function", IEEE Transaction on automatic control, 37(9), 1465-1470, 1992.

[31] A. Rabah, S. Ladaci, and M. Lashab, Bifurcation-based Fractional Order PI $\lambda \mathrm{D} \mu$ Controller Design Approach for Nonlinear Chaotic Systems. Frontiers of Information Technology \& Electronic Engineering, 19(2), 180-191, 2018.
[32] A. Bourouba, S. Ladaci, and A. Chaabi, Moth-flame optimisation algorithm-based fractional order $\mathrm{PI} \lambda \mathrm{D} \mu$ controller with MRAC tuning configuration. International Journal of Systems, Control and Communications, 9(2), 148-171, 2018.

[33] A. Valério, and J. S. D. Costa, Tuning of Fractional PID Controllers with ZieglerNichols-Type Rules. Signal Process, 86, 2771-2784, 2006.

[34] J.G. Ziegler, and N. B. Nichols, Optimum Settings for Automatic Controllers. Transactions of the A.S.M.E. 759-765, 1942.

[35] D.P. Atherton, N. Tan, and A. Yüce, Methods for computing the time response of fractional-order systems. IET Control Theory and Applications, 9(7), 817-830, 2014.

[36] A. Yüce, N. Tan, and D.P. Atherton, Fractional Order PI Controller Design for Time Delay Systems. IFACPapersOnLine, 49(10), 94-99, 2016.

[37] P. Shaha, and S. Agashe, Review of fractional PID controller. Mechatronics, 38, 29-41, 2016. 